\title{
Analysis on Cognitive Behaviors and Prevention of Human Errors of Coalmine Hoist Drivers
}

\author{
Pengye Zhu ${ }^{1}$, Linhui Sun ${ }^{1 *}$, Yunfeng Song ${ }^{2}$, Liao Wang $^{1}$, Xiaofang Yuan ${ }^{1}$, Zong Dai ${ }^{3}$ \\ ${ }^{1}$ School of Management, Xi' an University of Science and Technology, Xi'an 710054, China \\ ${ }^{2}$ School of Management, China University of Mining and Technology-Beijing, Beijing 100083, China \\ ${ }^{3}$ Hetaoyu Coal Mine, Huaneng Qingyang Coal and Electricity Co., Ltd., Qingyang 745300, China
}

Corresponding Author Email: linhuisun@xust.edu.cn

https://doi.org/10.18280/ijsse.100511

Received: 8 May 2020

Accepted: 12 August 2020

\section{Keywords:}

cognitive behaviors, human errors, coalmine, hoist drivers

\begin{abstract}
Human errors are commonplace among hoist drivers in the hoisting task of coalmines. To reduce these errors and prevent accidents, it is necessary to identify the features of cognitive behaviors and main cognitive errors of the hoist drivers. This paper analyzes the accident cases and operating flow of coalmine hoist, and establishes a cognitive process model of coalmine hoist drivers. Further, the cognitive behaviors and functions of the drivers were analyzed stage by stage, revealing the distributions of their main cognitive behaviors and functions. It is learned that most coalmine hoist accidents concentrate in two stages: lifting, and operation monitoring. The operating processes in the two stages were further deliberated. The specific operations were extracted as the influencing factors of human errors, and the importance of each index was calculated through analytic hierarchy process (AHP). The research results provide a theoretical reference for identifying the key factors affecting the human errors of the operations by coalmine hoist drivers, and shed new light on how to prevent such errors.
\end{abstract}

\section{INTRODUCTION}

In industrial systems, $70 \%-90 \%$ of all events are related to human behaviors [1], and $60 \%-90 \%$ of system failures are attributable to human errors [2]. For example, the nuclear accidents at Three Mile Island and Chernobyl were directly caused by human errors. When it comes to China, 1,175 out of 1,203 (>97.67\%) major coalmine accidents are resulted from human factors [3]. Therefore, coalmines across China attach special importance to safety management and human reliability research.

In China's coal industry, the construction of smart mines is the common pursuit of numerous enterprises. With the proliferation of emerging technologies, the main tasks of monitoring operators have changed from patrolling and manual operations in the control room to monitoring and control on computer screens. In other words, the operator's work has become more and more cognitive [4-6].

Mine hoist, a.k.a. mine elevator or winch, is a simple lift. As shown in Figure 1, the hoist room serves as the personnel and material transport center of the coalmine, bridging the underground with the ground. The digitization of the hoist room has brought multiple changes to the hoist drivers, from their role and work mode, the content and method of humansystem interaction, the factors affecting cognitive behaviors and errors, to the complexity of tasks. Faced with increasingly complex operation tasks and information, the hoist drivers must process complex information quickly, and make accurate judgement and decisions.

Studies have shown that visual information accounts for about $80 \%$ of all exchanged information [7], and $76 \%$ of all errors in situational awareness are the result of neglecting necessary information (selective attention failure) [8]. Human errors could be based on knowledge, rules, and skills. Skillbased errors refer to the errors made in frequent, simple, and familiar operations. The reason is low concentration or focusing on only one point.

In the coalmine, the hoist drivers are exposed to various information channels. They need to continuously receive and process various screen information, and instrument data, and quickly respond to all sorts of alarms or abnormal data. Take the monitoring task for example. The hoist drivers should respond to audiovisual signals from numerous displays of computer numerically controlled (CNC) systems and monitors of computers, and start or stop the hoist accordingly. In addition, the information from each channel needs to be cognized, processed, and handled, according to the task requirements or priority levels.

In the early stage of digital development, the humanmachine-task system has not reached the well adapted state. This brings about many new human errors and safety problems, namely, the errors in monitoring, judgement and operation induced by the keyhole effect and cognitive overload. The digital control system further complicates the situation of the drivers. The management task of the digital interface may distract the drivers, making it difficult to call a monitoring interface or acquire the necessary information for monitoring. It may also cause the heavily-loaded drivers to have errors (e.g., delay and failure) in target positioning, auditory errors, and incorrect decisions, which in turn lead to mis-operations, and safety accidents in severe cases $[9,10]$.

Through the above analysis, this paper deeply analyzes the operation procedure of hoisting in view of coalmine hoist accidents, examines the psychological activities and 
situational awareness of the hoist drivers, and classifies their cognitive behaviors and errors. The research results help to reduce the human errors of coalmine hoist drivers in monitoring operations and prevent serious accidents.

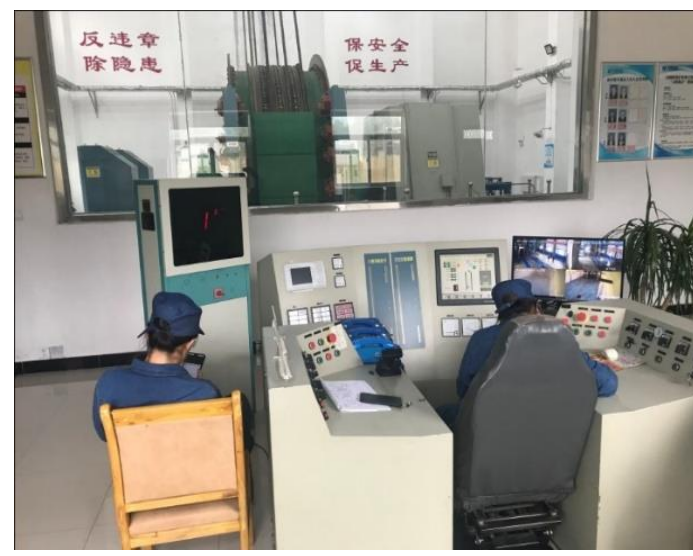

Figure 1. The console of the hoist room

\section{ANALYSIS ON COGNITIVE BEHAVIORS AND ERRORS}

\subsection{Theoretical basis of cognitive model}

Our cognition of external things or stimuli depends on the features of the object, and the processing by the brain. It is a complex process reflecting the connection between things and human. The processing includes a bottom-up mode focusing on the saliency of the stimulus information (size, color, brightness, etc.), and a top-down mode affected by subjective knowledge and experience, and motivational needs. The two modes jointly affect our physical and mental activities, such as perception, feeling, attention, memory, and language [11]. Human has been striving to scientifically model our cognitive process, and explain our cognitive behaviors or errors.

To date, many cognitive behavior models have been established. For instance, the stimulus-organism-response (S$\mathrm{O}-\mathrm{R}$ ) model explains the impact of the environment on human behaviors [12]. The Wickens' human information processing model describes a series of processing stages (psychological operations), and illustrates the information flow of humans completing an operational task, providing a suitable tool to analyze the psychological processing during human-system interaction [13]. The information decision action in a crew (IDAC), a personnel information cognition model, encompasses such four modules as information processing, diagnosis and decision-making, action execution, and mental state. The model emphasizes the continuous circulation of the interaction process, and highlights the interaction between mental state and other modules [14]. Rasmussen proposed a step ladder model of the decision-making process called skillsrules-knowledge (SRK) behavior model [15, 16]. Reason developed a general accident investigation and analysis model, pointing out that the accident occurred due to the simultaneous failure of factors at all levels of the system [17]. The above cognitive models cannot adapt to the behavior analysis of the hoist drivers in the digital hoist room. To build up a suitable model, it is important to analyze the cognitive behaviors of the hoist drivers according to their tasks and operation processes.

Like the main control room in nuclear power plants (hereinafter referred to as the main control room), the hoist room in coalmines have adopted digital control systems. In these digital rooms, the main tasks of the operator have changed from manual operations to the monitoring and control of computer monitors [4-6]. The human-computer interaction (HCI) scenarios between the main control room and the hoist room are highly similar. Both rooms have numerous meters, screens, and control buttons, and require a high cognitive level of the operator. Lee et al. put forward a cognitive process model of the personnel in the main control room, which clarifies the relationships between personnel, human machine interface (HMI), instrument and control system (I\&C), and the power plant [18]. In the complex human-machine environment, the cognitive behaviors of personnel can be divided to monitoring and detection; situation assessment; response planning; response implementation [19].

Referring to the cognitive process model of the personnel in the main control room, this paper develops a cognitive process model (Figure 2) of coalmine hoist drivers, based on the working situation of the drivers and a technique for human event analysis (ATHEANA) [20]. Note that this model focuses on the connection between the hoist drivers, operation process, cognitive behaviors, HMI, I\&C, and hoist room environment, rather than the cognitive or information processing in human brain.

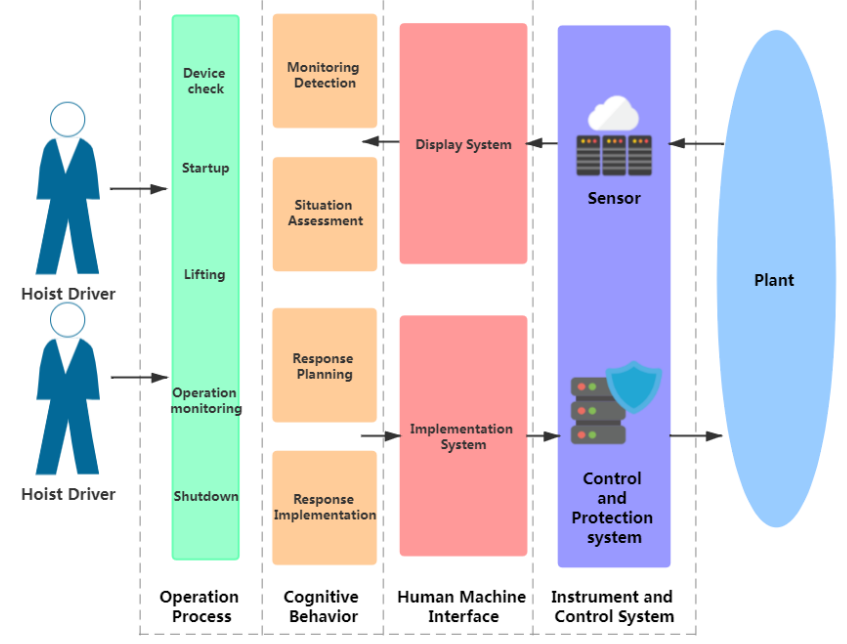

Figure 2. The cognitive process model of coalmine hoist drivers

\subsection{Analysis of behaviors and errors based on cognitive process model}

In general, the standard operation procedure (SOP) of the hoist drivers includes five stages: device check, startup, lifting, operation monitoring, and shutdown. During the operation of the hoist room, the operation tasks are mainly controlled semiautomatically, except for shutdown and maintenance. This control mode features uninterrupted operation, frequent starts and stops, and various loading tasks (e.g. personnel lifting, material lifting, and explosive lifting).

Considering the variety of display instruments and controllers in the hoist room, this paper analyzes the cognitive behaviors of the hoist drivers in each stage of operation under semi-automatic control mode. In addition, the hoister accidents were extracted from the data on China's coalmine accidents $[21,22]$, and combined with the direct and indirect 
causes in accident investigation reports. After simple analysis and evaluation, the combined data were matched with the corresponding operation stages. The analysis results on the cognitive behaviors of the hoist drivers in the five stages are displayed in Tables 1-3.

Table 1. The analysis results on the cognitive behaviors of the hoist drivers in device check

\begin{tabular}{|c|c|c|c|c|c|}
\hline Stage & Operation & $\begin{array}{l}\text { Cognitive } \\
\text { behavior }\end{array}$ & $\begin{array}{l}\text { Cognitive } \\
\text { function }\end{array}$ & $\begin{array}{c}\text { Potential } \\
\text { error }\end{array}$ & $\begin{array}{c}\text { Remark } \\
\text { (accident case) }\end{array}$ \\
\hline \multirow{5}{*}{$\begin{array}{l}\text { 1. Device } \\
\text { check }\end{array}$} & $\begin{array}{c}\text { 1.1 Check the condition of electrical } \\
\text { equipment }\end{array}$ & $\begin{array}{l}\text { Audiovisual } \\
\text { observation }\end{array}$ & $\begin{array}{c}\text { Thinking and } \\
\text { decision }\end{array}$ & $\begin{array}{l}\text { Incomplete } \\
\text { check }\end{array}$ & $\begin{array}{l}\text { The aging of the electronic control system } \\
\text { caused a fire in the control room. }\end{array}$ \\
\hline & 1.2 Check the console & $\begin{array}{l}\text { Audiovisual } \\
\text { observation }\end{array}$ & $\begin{array}{l}\text { Thinking and } \\
\text { decision }\end{array}$ & Misread & \\
\hline & 1.3 Check the hydraulic system & $\begin{array}{l}\text { Audiovisual } \\
\text { observation }\end{array}$ & $\begin{array}{l}\text { Thinking and } \\
\text { decision }\end{array}$ & $\begin{array}{l}\text { Incomplete } \\
\text { check }\end{array}$ & \\
\hline & $\begin{array}{l}\text { 1.4 Check the ventilation and cooling } \\
\text { system of the motor }\end{array}$ & $\begin{array}{l}\text { Audiovisual } \\
\text { observation }\end{array}$ & $\begin{array}{c}\text { Thinking and } \\
\text { decision }\end{array}$ & $\begin{array}{l}\text { Incomplete } \\
\text { check }\end{array}$ & \\
\hline & 1.5 Check the signal system & $\begin{array}{l}\text { Audiovisual } \\
\text { observation }\end{array}$ & $\begin{array}{l}\text { Thinking and } \\
\text { decision }\end{array}$ & Misread & \\
\hline
\end{tabular}

Table 2. The analysis results on the cognitive behaviors of the hoist drivers in startup and lifting

\begin{tabular}{llcccc}
\hline Stage & Operation & $\begin{array}{c}\text { Cognitive } \\
\text { behavior }\end{array}$ & $\begin{array}{c}\text { Cognitive } \\
\text { function }\end{array}$ & $\begin{array}{c}\text { Potential } \\
\text { error }\end{array}$ & $\begin{array}{c}\text { Remark } \\
\text { (accident case) }\end{array}$ \\
\hline
\end{tabular}

\subsection{Turn the "System open, close, start" knob to the start position \\ 2.2 Start the cooling fan \\ 2.3 Close the high pressure switch \\ 2.4 Press the fault reset button}

2.

Startup $\quad 2.5$ Close the safety circuit switch

2.6 Check that the console has no fault display

\subsection{Choose semi-automatic lifting}

2.8 Set the running position to the light load position

3. 3.1 Receive and confirm the audiovisual signal Audiovisual Lifting about the personnel (material/explosive) lifting

3.2 Observe the up-hole and downhole video displays

3.3 Adjust the speed mode to $5 \mathrm{~m} / \mathrm{s}(11 \mathrm{~m} / \mathrm{s}$

$$
/ 2 \mathrm{~m} / \mathrm{s})
$$

3.4 Receive up and down $(2,3)$ audiovisual signals

3.5 Confirm whether the cage position on the depth indicator matches the signal

3.6 Confirm the direction of the speed mode

$\mathrm{knob}$, and that the hoisting speed on the hoist screen is $5 \mathrm{~m} / \mathrm{s}(10 \mathrm{~m} / \mathrm{s} / 2 \mathrm{~m} / \mathrm{s})$

3.7 Observe the monitoring video on the

external scene, and verify whether the

personnel enter the cage and wellhead normally

3.8 Press the semi-automatic start button

Audiovisual behavior

knob

Pressing the knob

Pressing the knob

Pressing the knob

Pressing the knob

Audiovisual

observation

Pressing the knob

Pressing the knob

observation

observation

Pressing the

knob

Audiovisual

observation

Recognition

Recognition

Audiovisual

observation

Thinking and decision

Pressing the knob decision
Memory/learning Not at the right

position

Memory/learning

Not started

Memory/learning Not successful

Memory/learning

Memory/learning

Memory/learning

Memory/learning Wrong

selection

Memory/learning Wrong running

Thinking and Wrong Signal update was not timely and decision confirmation inaccurate, causing casualties.

Memory/learning Misread

Thinking and Adjustment decision error

Memory/learning Misread

Thinking and

Wrong confirmation

Wrong confirmation

The personnel were lifted at an excessively high speed.

Misread The operation was performed without verifying the safe entry and exit of personnel and materials, causing casualties.

Memory/learning Wrong button The drivers pressed a wrong button.
With the development of digitalization, many complex tasks of the hoist monitoring system have been automatized. Now, most operations depend heavily on the cognitive performance of the hoist drivers.

In the device check stage, the hoist drivers mainly rely on their cognitive behavior and ability to evaluate states. The state evaluation operations are relatively easy, including the check of equipment, system, hydraulic pressure, temperature, etc. During these operations, the possible cognitive errors are incorrect, insufficient, delayed, and missed state interpretations [23].

The main cognitive performance lies in information comparison, i.e. comparing the operating state or parameter with the standard parameter or threshold range specified in the operating procedures of the post. If the system configuration is complex or advanced, information integration and state understanding are another two cognitive tasks: the hoist drivers need to judge and recognize multiple states, and then determine the overall operating state of the system, e.g. whether the system reaches the startup condition, and whether 
it is necessary to predict the system state and execute response plan.

Note that the hoist drivers should conduct routine checks once every $2 \mathrm{~h}$, apart from the device check before the startup of the hoist.

During startup and lifting, the hoist drivers mainly rely on their cognitive behavior and ability to respond to execution commands. Command executions require real interactions between the drivers and the control system, such as turning a knob, and opening a switch. The possible cognitive errors can be summarized as missing, wrong, and insufficient operations. Missing operation means the omission of necessary procedures during the operation; wrong operation refer to incorrect targets or actions, i.e. implementing a command on a wrong target, or operating in a wrong sequence, and making a wrong record; insufficient operation refer to excessively long or short operation, or delayed operation (e.g. the drivers do not start up the hoist long after receiving the hoist signal).

During operation monitoring and shutdown, the hoist drivers are mainly responsible for monitoring and detection.
The key is to stay attentive and alert, and search for information through the down and bottom-up attention mechanisms.

The bottom-up attention mechanism is affected by the visual saliency of the object and the search effort. The visual regions of interest (ROIs) differ in the size, color, and contrast of the information displayed. Through complex visual processing, each influencing factor is processed into a saliency map of comprehensive features. The most salient region is more likely to attract attention [24-26]. Information spacing also affects the shift of attention. The hoist drivers will be more inclined to choose the easier-to-obtain information, which are close to the center of the line of sight (LOS), rather than strive to acquire other information resources that are more difficult to obtain. Under the effect of the layout of external space, each visual ROI will have a unique spatial distance and spatial separation (perspective angle). With the growth in the distance and the angle, the movements of the hoist drivers for information acquisition gradually escalate from no rotation, eye movement, head and neck movement, to limb movement.

Table 3. The analysis results on the cognitive behaviors of the hoist drivers in operation monitoring and shutdown

\begin{tabular}{|c|c|c|c|c|c|}
\hline Stage & Operation & $\begin{array}{l}\text { Cognitive } \\
\text { behavior }\end{array}$ & $\begin{array}{l}\text { Cognitive } \\
\text { function }\end{array}$ & $\begin{array}{c}\text { Potential } \\
\text { error }\end{array}$ & $\begin{array}{c}\text { Remark } \\
\text { (accident case) }\end{array}$ \\
\hline \multirow{9}{*}{$\begin{array}{l}\text { 4. Operation } \\
\text { monitoring }\end{array}$} & $\begin{array}{l}\text { 4.1 Check whether the stator current exceeds the } \\
\text { limit (if it exceeds } 2 \mathrm{kV} \text {, make a record and } \\
\text { contact the wellhead for notification) }\end{array}$ & Recognition & $\begin{array}{l}\text { Thinking and } \\
\text { decision }\end{array}$ & Misread & $\begin{array}{l}\text { The sudden change of current } \\
\text { was not recorded in time or } \\
\text { treated as an emergency. }\end{array}$ \\
\hline & $\begin{array}{c}\text { 4.2 Check whether the speed values in the } \\
\text { speedometer, and the hoist screen increase at a } \\
\text { uniform rate }\end{array}$ & Recognition & $\begin{array}{l}\text { Thinking and } \\
\text { decision }\end{array}$ & Misread & \multirow{8}{*}{$\begin{array}{c}\text { The personnel were lifted at an } \\
\text { excessively high speed. }\end{array}$} \\
\hline & $\begin{array}{l}\text { 4.3 Record the lifting time, loading type, etc. in } \\
\text { the Auxiliary Shaft Lifting Record Form }\end{array}$ & $\begin{array}{l}\text { Handwritten } \\
\text { recording }\end{array}$ & Memory/learning & Record error & \\
\hline & $\begin{array}{l}\text { 4.4 Observe whether the lifting speed reaches } \\
\text { the normal operating speed of } 5 \mathrm{~m} / \mathrm{s}(10 \mathrm{~m} / \mathrm{s})\end{array}$ & Recognition & $\begin{array}{l}\text { Thinking and } \\
\text { decision }\end{array}$ & $\begin{array}{l}\text { Wrong } \\
\text { confirmation }\end{array}$ & \\
\hline & $\begin{array}{l}4.5 \text { Freely monitor and wait for various signal } \\
\text { indications (voltage, current, oil pressure, speed, } \\
\text { cage position, etc.) }\end{array}$ & $\begin{array}{l}\text { Audiovisual } \\
\text { observation }\end{array}$ & $\begin{array}{l}\text { Attention and } \\
\text { alertness }\end{array}$ & Misread & \\
\hline & $\begin{array}{l}\text { 4.6 Randomly observe whether the stator current } \\
\text { is abnormal (usually at the parallel nodes of the } \\
\text { large and small cages) }\end{array}$ & $\begin{array}{l}\text { Audiovisual } \\
\text { observation }\end{array}$ & $\begin{array}{l}\text { Thinking and } \\
\text { decision }\end{array}$ & Misread & \\
\hline & $\begin{array}{l}\text { 4.7 Observe whether the "Slowdown Zone" on } \\
\text { the luminescent plate flashes and alert the other } \\
\text { driver in voice }\end{array}$ & $\begin{array}{l}\text { Audiovisual } \\
\text { observation }\end{array}$ & $\begin{array}{l}\text { Thinking and } \\
\text { decision }\end{array}$ & $\begin{array}{l}\text { Misread or } \\
\text { misheard }\end{array}$ & \\
\hline & $\begin{array}{c}4.8 \text { Observe whether the speed in the } \\
\text { speedometer decreases at a uniform rate }\end{array}$ & Recognition & $\begin{array}{l}\text { Thinking and } \\
\text { decision }\end{array}$ & Misread & \\
\hline & $\begin{array}{l}\text { 4.9 Check whether the stator current is within a } \\
\text { reasonable range }\end{array}$ & Recognition & $\begin{array}{l}\text { Thinking and } \\
\text { decision }\end{array}$ & $\begin{array}{l}\text { Wrong } \\
\text { confirmation }\end{array}$ & \\
\hline \multirow[t]{6}{*}{ 5. Shutdown } & $\begin{array}{l}\text { 5.1 Receive the audiovisual signal of shutdown, and } \\
\text { shutdown the hoist }\end{array}$ & $\begin{array}{l}\text { Audiovisual } \\
\text { observation }\end{array}$ & Memory/learning & Misread & \\
\hline & $\begin{array}{c}5.2 \text { Observe whether the depth indicator, speed, and } \\
\text { current data are zeroed }\end{array}$ & $\begin{array}{l}\text { Audiovisual } \\
\text { observation }\end{array}$ & $\begin{array}{l}\text { Thinking and } \\
\text { decision }\end{array}$ & Misread & \\
\hline & 5.3 Observe whether the green light of the & & & Misread & \\
\hline & $\begin{array}{l}\text { shutdown point, monitoring point, deceleration } \\
\text { point, and correction point on the hoist screen } \\
\text { are on }\end{array}$ & $\begin{array}{l}\text { Audiovisual } \\
\text { observation }\end{array}$ & $\begin{array}{l}\text { Thinking and } \\
\text { decision }\end{array}$ & & \\
\hline & \multirow{2}{*}{$\begin{array}{l}5.4 \text { Observe the monitoring video on the } \\
\text { external scene, and verify whether the personnel } \\
\text { enter the cage and wellhead normally } \\
5.5 \text { Fill in work records }\end{array}$} & $\begin{array}{l}\text { Audiovisual } \\
\text { observation }\end{array}$ & $\begin{array}{l}\text { Thinking and } \\
\text { decision }\end{array}$ & Misread & \\
\hline & & $\begin{array}{l}\text { Handwritten } \\
\text { recording }\end{array}$ & Memory/learning & Record error & \\
\hline
\end{tabular}




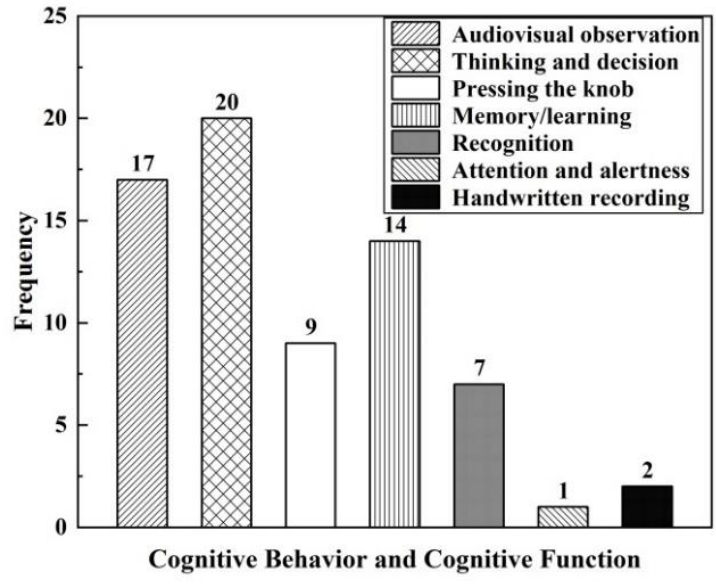

Figure 3. The distributions of the main cognitive behaviors and functions of the hoist drivers

The top-down attention mechanism is essentially the lowlevel perceptual judgment driven by subjective high-level wills, including subjective expectation, value, knowledge, and experience of the hoist drivers. Specifically, the expectation refers to the bandwidth and rate of change of information, while the value stands for the usefulness or importance of information $[27,28]$. The attention distribution of the hoist drivers is very uncertain. During the monitoring of screens and instruments, they mainly subjectively evaluate the importance of parameters based on knowledge and experience. If the attention resources are not properly allocated, information search errors might occur during operation monitoring and shutdown, namely, missing information, wrong collection, and insufficient collection.

According to the analysis on the cognitive behaviors and functions of the hoist drivers at each stage in Tables 1-3, the authors plotted the distributions of the main cognitive behaviors and functions of the hoist drivers.

From Tables 1-3 and Figure 3, it can be seen that lifting and operation monitoring are susceptible to human errors and related hoist accidents, while device check, startup, and shutdown are prone to accidents caused by mechanical and electrical failures, instead of those induced by human errors. The main reasons are as follows:

Lifting and operation monitoring are the core stages of the operation process. Directly related to the hoisting task, the two stages consume more attention resources and the ability of thinking and decision-making. By contrast, device check, startup, and shutdown require relatively simple cognitive abilities. Most hoist rooms support automatic shutdown, without needing any cognitive resource in the shutdown stage.

Therefore, this article decides to further discriminate the key influencing factors of human errors during the lifting and operation monitoring of coalmine hoisting.

\section{IMPORTANCE ANALYSIS}

\subsection{Construction of hierarchical structure and matrix}

The analytic hierarchy process (AHP) aims to decompose a problem into multiple orderly levels, and then quantifies the relative importance of each level based on the judgment of objective reality [29]. This section introduces the AHP to analyze the process indices of the lifting and operation monitoring of the hoisting task. The collected data were rated by experts and further processed.

The goal layer covers the key operation indices of coalmine hoist drivers; the criterion layer contains lifting A1 and operation monitoring A2; the alternative layer includes receive and confirm the audiovisual signal B1, observe video displays $\mathrm{B} 2, \ldots$, check whether the stator current is within a reasonable range B17.

Scoring forms were distributed among safety management professors, coalmine safety supervisors, and coalmine hoist drivers. A total of 5 valid scoring forms were returned. The medium of each index was taken as the final expert score. On this basis, the pairwise comparison matrix was established for each influencing factor of the human errors of coalmine hoist drivers (Tables 4-6).

Table 4. The pairwise comparison matrix of relative importance between primary indices

\begin{tabular}{ccc}
\hline $\mathbf{A}$ & Lifting $\mathbf{A}_{\mathbf{1}}$ & Operation monitoring $\mathbf{A}_{\mathbf{2}}$ \\
\hline Lifting $\mathrm{A}_{1}$ & 1 & 2 \\
Operation & $1 / 2$ & 1 \\
monitoring $\mathrm{A}_{2}$ & & 1 \\
\hline
\end{tabular}

Table 5. The pairwise comparison matrix of relative importance between secondary indices under A1

\begin{tabular}{ccccccccc}
\hline $\mathbf{A}_{\mathbf{1}}$ & $\mathbf{B}_{\mathbf{1}}$ & $\mathbf{B}_{\mathbf{2}}$ & $\mathbf{B}_{\mathbf{3}}$ & $\mathbf{B}_{\mathbf{4}}$ & $\mathbf{B}_{5}$ & $\mathbf{B}_{\mathbf{6}}$ & $\mathbf{B}_{7}$ & $\mathbf{B}_{\mathbf{8}}$ \\
$\mathbf{B}_{\mathbf{1}}$ & 1 & $11 / 2$ & $5 / 2$ & 4 & $5 / 2$ & $9 / 2$ & $7 / 2$ & 5 \\
$\mathbf{B}_{2}$ & $2 / 11$ & 1 & $1 / 3$ & $5 / 12$ & $1 / 3$ & $4 / 15$ & $11 / 60$ & $1 / 4$ \\
$\mathbf{B}_{3}$ & $2 / 5$ & 3 & 1 & $11 / 4$ & 1 & $5 / 2$ & 3 & 4 \\
$\mathbf{B}_{4}$ & $1 / 4$ & $12 / 5$ & $4 / 11$ & 1 & $4 / 11$ & $5 / 4$ & $13 / 8$ & $13 / 6$ \\
$\mathbf{B}_{5}$ & $2 / 5$ & 3 & 1 & $11 / 4$ & 1 & $5 / 2$ & 2 & 3 \\
$\mathbf{B}_{6}$ & $2 / 9$ & $15 / 4$ & $2 / 5$ & $4 / 5$ & $2 / 5$ & 1 & $6 / 7$ & $7 / 4$ \\
$\mathbf{B}_{7}$ & $2 / 7$ & $60 / 11$ & $1 / 3$ & $8 / 13$ & $1 / 2$ & $7 / 6$ & 1 & 2 \\
$\mathbf{B}_{\mathbf{8}}$ & $1 / 5$ & 4 & $1 / 4$ & $6 / 13$ & $1 / 3$ & $4 / 7$ & $1 / 2$ & 1 \\
\hline
\end{tabular}

Table 6. The pairwise comparison matrix of relative importance between secondary indices under A2

\begin{tabular}{cccccccccc}
\hline $\mathbf{A}_{\mathbf{2}}$ & $\mathbf{B}_{9}$ & $\mathbf{B}_{10}$ & $\mathbf{B}_{\mathbf{1 1}}$ & $\mathbf{B}_{\mathbf{1 2}}$ & $\mathbf{B}_{\mathbf{1 3}}$ & $\mathbf{B}_{\mathbf{1 4}}$ & $\mathbf{B}_{\mathbf{1 5}}$ & $\mathbf{B}_{\mathbf{1 6}}$ & $\mathbf{B}_{\mathbf{1 7}}$ \\
$\mathbf{B}_{\mathbf{9}}$ & 1 & $5 / 2$ & 5 & $7 / 20$ & $7 / 12$ & $5 / 12$ & $1 / 5$ & $5 / 8$ & 2 \\
$\mathbf{B}_{\mathbf{1 0}}$ & $5 / 2$ & 1 & $7 / 2$ & $5 / 24$ & $9 / 28$ & $9 / 40$ & $1 / 6$ & $7 / 20$ & $3 / 4$ \\
$\mathbf{B}_{11}$ & $1 / 5$ & $2 / 7$ & 1 & $13 / 84$ & $7 / 45$ & $6 / 35$ & $15 / 102$ & $11 / 60$ & $7 / 24$ \\
$\mathbf{B}_{12}$ & $20 / 7$ & $24 / 5$ & $84 / 13$ & 1 & $9 / 8$ & $7 / 4$ & $5 / 12$ & 2 & 4 \\
$\mathbf{B}_{13}$ & $12 / 7$ & $28 / 9$ & $45 / 7$ & $8 / 9$ & 1 & $8 / 3$ & $21 / 10$ & 2 & 4 \\
$\mathbf{B}_{14}$ & $12 / 5$ & $40 / 9$ & $35 / 6$ & $4 / 7$ & $3 / 8$ & 1 & $7 / 20$ & $10 / 6$ & 5 \\
$\mathbf{B}_{15}$ & 5 & 6 & $102 / 15$ & $12 / 5$ & $10 / 21$ & $20 / 7$ & 1 & $7 / 2$ & $11 / 2$ \\
$\mathbf{B}_{16}$ & $8 / 5$ & $20 / 7$ & $60 / 11$ & $1 / 2$ & $21 / 2$ & $6 / 10$ & $2 / 7$ & 1 & 3 \\
$\mathbf{B}_{17}$ & $1 / 2$ & $4 / 3$ & $24 / 7$ & $1 / 4$ & $1 / 4$ & $1 / 5$ & $2 / 11$ & $1 / 3$ & 1 \\
\hline
\end{tabular}

\subsection{Consistency check}

To ensure its validity, each judgement matrix needs to pass through the consistency check. First, the indices on each layer were ranked by their importance relative to an index on the upper layer. The weight coefficient of each index can be computed by the judgement matrix:

$$
W_{i}=a_{i j} / \sum_{i=1}^{n} a_{i j} \quad i, j=1,2, \ldots n
$$

where, $W_{i}$ is the weight of the i-th index; $a_{i j}$ is the ratio of the $\mathrm{i}$-th index to the $\mathrm{j}$-th index. Dividing each index by the sum of each column and normalizing the matrix: 


$$
\mathrm{A}=\left[\begin{array}{cccc}
a_{11} & a_{12} & \cdots & a_{1 n} \\
a_{21} & a_{22} & \cdots & a_{2 n} \\
\vdots & \vdots & \vdots & \vdots \\
a_{n 1} & a_{n 2} & \cdots & a_{n n}
\end{array}\right]
$$

Then, the normalized vector of the maximum eigenvalue was obtained by averaging the elements in each row. The maximum eigenvalue $\lambda_{\max }$ of the matrix can be calculated by:

$$
\lambda_{\max }=\sum_{i=1}^{n} \frac{(A W)_{i}}{n W_{i}} \quad i=1,2 \ldots n
$$

Next, the consistency index CI can be calculated by:

$$
C I=\frac{\lambda_{\max }-n}{n-1}
$$

where, $n$ is the order of the matrix. For the first matrix, when $n=2$, the positive and negative matrices of the second-order matrix are the same, eliminating the need for consistency test. When $n>2$, the random consistency ratio $C R$ was introduced to represent the consistency of the matrix: $C R=C I / R I$, where RI is the mean random consistency index, whose values are given in Table 7.

Table 7. The $R I$ values of matrices of orders 1-10

$$
\begin{array}{ccccccccc}
\hline \text { Order12 } & \mathbf{3} & \mathbf{4} & \mathbf{5} & \mathbf{6} & \mathbf{7} & \mathbf{8} & \mathbf{9} & \mathbf{1 0} \\
\hline R I & 000 & 580 & 901 & 121 & 241 & 321 &
\end{array}
$$

\begin{tabular}{ll}
$R I$ & 000.580 .901 .121 .241 .321 .411 .451 .49 \\
\hline
\end{tabular}

Through the calculation, it is obtained that: $n=2$, weight coefficients $W=(0.6667,0.3333) ; n=8, \lambda_{\max }=8.0095$, weight coefficients $W 1=(0.3136,0.0346,0.1778,0.0876,0.1603$, $0.0781,0.0907,0.0575), \quad C I=0.0667, \quad C R=0.0473 ; \quad n=9$, $\lambda_{\max }=9.0157$, Weight coefficients $W 2=(0.0705,0.0522,0.0189$, $0.1618,0.2032,0.1235,0.2403,0.0898,0.0399), C I=0.1267$, $C R=0.0873$.
Next, the importance of each index relative to the goal layer was calculated for consistency check. The consistency index $C I$ can be calculated by:

$$
C I=\sum_{i=1}^{m} a_{i} C I_{i}
$$

where, $C I_{i}$ is the mean random consistency index of layer B corresponding to ai. The mean random consistency index $R I$ can be calculated by:

$$
R I=\sum_{i=1}^{m} a_{i} R I_{i}
$$

where, $R I_{i}$ is the mean random consistency index of layer $\mathrm{B}$ corresponding to ai. The random consistency ratio $\mathrm{CR}$ can be calculated by:

$$
C R=C I / R I
$$

Through calculation, it is obtained that: $C I=0.6667 \times$ $0.0667+0.3333 \times 0.1267=0.0867, R I=0.6667 \times 1.41+$ $0.3333 \times 1.45=1.423, \mathrm{CR}=0.0867 \div 1.423=0.0609$. Since $C R$ is smaller than 0.1 , the results have good consistency. The AHP results are shown in Table 8, where the comprehensive weight is the product between the weight of each secondary index and that of the corresponding primary index.

As shown in Table 8, the top 8 influencing factors of the human errors of coalmine hoist drivers are: receive and confirm the audiovisual signal (0.2091), adjust the speed mode (0.1185), Confirm cage position (0.1069), observe whether the "Slowdown Zone" on the luminescent plate flashes and alert

\begin{tabular}{|c|c|c|c|c|c|}
\hline \multirow{2}{*}{ Primary index } & \multirow{2}{*}{$\begin{array}{c}\text { Weight } \\
0.6667\end{array}$} & Secondary index & Weight & \multicolumn{2}{|c|}{ Comprehensive weight Ranking } \\
\hline & & Receive and confirm the audiovisual signal B1 & 0.3136 & 0.2091 & 1 \\
\hline & & Observe video displays B2 & 0.0346 & 0.0231 & 14 \\
\hline & & Adjust the speed mode B3 & 0.1778 & 0.1185 & 2 \\
\hline & & Receive up and down audiovisual signals B4 & 0.0876 & 0.0584 & 7 \\
\hline & & Confirm cage position B5 & 0.1603 & 0.1069 & 3 \\
\hline & & $\begin{array}{l}\text { Confirm the direction of the speed mode knob, and the } \\
\text { hoisting speed on the hoist screen B6 }\end{array}$ & 0.0781 & 0.0521 & 9 \\
\hline & & Verify the personnel and wellhead situation B7 & 0.0907 & 0.0605 & 6 \\
\hline & & Press the semi-automatic start button B8 & 0.0575 & 0.0383 & 11 \\
\hline \multirow{9}{*}{\multicolumn{2}{|c|}{ Operating monitoring $\mathrm{A}_{2} 0.3333$}} & Check whether the stator current exceeds the limit B9 & 0.0705 & 0.0235 & 13 \\
\hline & & $\begin{array}{l}\text { Check whether the speed values in the speedometer, and the } \\
\text { hoist screen increase at a uniform rate B10 }\end{array}$ & 0.0522 & 0.0174 & 15 \\
\hline & & Fill in the Auxiliary Shaft Lifting Record Form B11 & 0.0189 & 0.0063 & 17 \\
\hline & & Observe whether the lifting speed is normal B12 & 0.1618 & 0.0539 & 8 \\
\hline & & Perform free monitoring B13 & 0.2032 & 0.0677 & 5 \\
\hline & & Observe whether the stator current is abnormal B14 & 0.1235 & 0.0412 & 10 \\
\hline & & $\begin{array}{l}\text { Observe whether the "Slowdown Zone" on the luminescent } \\
\text { plate flashes and alert the other driver in voice B15 }\end{array}$ & 0.2403 & 0.0801 & 4 \\
\hline & & $\begin{array}{l}\text { Observe whether the speed in the speedometer decreases at a } \\
\text { uniform rate B } 16\end{array}$ & 0.0898 & 0.0299 & 12 \\
\hline & & $\begin{array}{l}\text { Check whether the stator current is within a reasonable range } \\
\qquad \mathrm{B} 17\end{array}$ & 0.0399 & 0.0133 & 16 \\
\hline
\end{tabular}
the other driver in voice $(0.0801)$, perform free monitoring (0.0677), verify the personnel and wellhead situation (0.0605), receive up and down audiovisual signals (0.0584), and observe whether the lifting speed is normal (0.0539). This ranking is consistent with the accident cases listed in Tables 1-3.

Table 8. The comprehensive weights 


\section{SUGGESTIONS AND COUNTERMEASURES}

Based on the AHP results, several measures were presented to prevent the human errors of coalmine hoist drivers from the angles of method, equipment, and management:

(1) Receive and confirm the audiovisual signal is the leading impactor of human errors. Coalmine accidents occur occasionally due to the untimely confirmation of signals. This type of accidents can be prevented by the following measures: change the position or angle for checking and sending signals; intensify the audiovisual signal, and increase the number of signal displays (in different areas) to attract driver attention; establish a supervisory team to check the degree of compliance of the operation; step up education and training of safety management, and improve the overall safety atmosphere.

(2) Concerning such indices as adjust the speed mode, confirm cage position, perform free monitoring, and verify the personnel and wellhead situation, the relevant human errors and accidents can be prevented by the following measures: remember the operating instructions through daily recitation, aiming to prevent missed and wrong operations; prepare identification cards according to the degree of importance, e.g. attach labels with different depths of colors next to different speed indicators to avoid accidents like lifting personnel at excessively high speed; upgrade the equipment and ban startup when the speed and other indices do not match the hoisting task or when the hoist is overload, thereby preventing lifting personnel at excessively high speed or overloading; implement strict check of shift rotation and on-site handover; go to work with a certificate; regularly patrol the site and check the compliance with the SOP; improve the reward and punishment system; improve the level of safety management.

In addition to the above key factors affecting human errors (e.g. operating method, equipment, and management), the working environment must also be considered. To improve the overall working environment, the hoist room must be kept clean, the ambient noise be minimized, the lighting brightness be adjusted timely, and the seats be made more comfortable.

\section{CONCLUSIONS}

The digitalization of coalmine hoist room has fundamentally changed the working environment and task situation of the hoist drivers. The SOP phases out the conventional mechanized and manual operation mode, raising new requirements on the cognitive behaviors and abilities of hoist drivers. This paper constructs the cognitive process model of coalmine hoist drivers, analyzes their cognitive behaviors and functions in each stage of the hoisting task, and scores and weights each key influencing factor. The main conclusions are as follows:

(1) The SOP of the hoist drivers includes five stages: device check, startup, lifting, operation monitoring, and shutdown. In these stages, the hoist drivers need to make use of multiple cognitive functions: thinking and decision-making, audiovisual observation, and memory/learning.

(2) During the execution of task operations, the hoist drivers mainly commit skill- and rule-based errors. Because the operation process is simple and repetitive, attention failure is very likely to occur, causing human accident. In the past, most human accidents of the hoist occur during lifting and operation monitoring. These two stages require the hoist drivers to perform recognition, information search, operation execution, and many other behaviors. The drivers are prone to be fatigued after staying alert for a long time.

(3) To avoid coalmine hoist accidents and improve safety management, the hoist room should be optimized continuously in many aspects following the ideas of industrial engineering, including personnel (load, knowledge and skills, experience), machinery (interface design, maintenance, layout), environment (lighting, noise), and management (scheduling, operating procedures, culture).

There are still some limitations in this research. For instance, the correlations between the influencing factors were not measured or discussed, and the proposed countermeasures need to be verified and further improved.

\section{ACKNOWLEDGEMENT}

This work is supported by the National Natural Science Foundation of China (Grant No.: 71673220) and the Headquarters of China Huaneng Group Co., Ltd. (Grant No.: HNMYKJ20-12).

\section{REFERENCES}

[1] Hollnagel, E. (1998). Cognitive Reliability and Error Analysis Method (CREAM). Cognitive Reliability \& Error Analysis Method, 262-275.

[2] He, X.H., Huang, X.R. (2007). Human Reliability Analysis in Industrial Systems: Principles, Methods and Applications. Beijing: Tsinghua University Press.

[3] Chen, H., Qi, H., Wang, O., Long, R.Y. (2007). The research on the structural equation model of affecting factors of deliberate violation in coalmine fatal accidents in China. Systems Engineering-Theory \& Practice, 27(8) 127-136. https://doi.org/10.1016/S1874-8651(08)600502

[4] Grozdanovic, M., Jankovic, Z. (2002). Interaction between human factors and the automatization. Working and Living environmental Protection, 2(2): 101-113.

[5] Chuang, C.F., Chou, H.P., Chen, Y.B., Shiao, H. (2008). Regulatory overview of digital I\&C system in Taiwan Lungmen project. Annals of Nuclear Energy, 35(5): 877889. https://doi.org/10.1016/j.anucene.2007.09.010

[6] Zio, E. (2009). Reliability engineering old problems and new challenges. Reliability Engineering, I\&C System Safety, 94(2): 125-141. https://doi.org/10.1016/j.ress.2008.06.002

[7] Jacobson, N., Bender, W. (1996). Color as a determined communication. IBM Systems Journal, 35(3.4): 526-538. https://doi.org/10.1147/sj.353.0526

[8] Jones, D.G., Endsley, M.R. (1996). Sources of situation awareness errors in aviation. Aviation Space \& Environmental Medicine, 67(6): 507-512.

[9] Zhang, L., Peng, H.L. (2017). Eye movement study in regard to the target location of the operator in the digitalized human-machine interface. Journal of Safety and Environment, 17(2): 577-581. https://doi.org/10.13637/j.issn.1009-6094.2017.02.034

[10] Zhang, L., Peng, H.L. (2015). Research on hearing errors and experimental verification of operator on digitalized human-machine interface. Industrial Engineering and Management, 20(3): 103-108. https://doi.org/10.3969/j.issn.1007-5429.2015.03.015 
[11] Moore, T., Zirnsak, M. (2017). Neural mechanisms of selective visual attention. Annual Review of Psychology, 68(1): 47-72. https://doi.org/0.1146/annurev-psych122414-033400

[12] Mehrabian, A., Russell, J.A. (1974). An Approach to Environmental Psychology. The MIT Press.

[13] Wickens, C. (1992). Engineering Psychology and Human Performance M. New York: HarperCollins.

[14] Sarter, N.B., Woods, D.D. (1995). How in the world did we ever get into that mode? Mode Error and Awareness in Supervisory Control. Human Factors, 37(1): 5-19. https://doi.org/10.1518/001872095779049516

[15] Rasmussen, J. (1983). Skills, rules, and knowledge; signals, signs, and symbols, and other distinctions in human performance models. Systems, Man and Cybernetics, 13(3): 257-266. https://doi.org/10.1109/TSMC.1983.6313160

[16] Rasmussen, J. (1986). Information Processing and Human-Machine Interaction: An Approach to Cognitive Engineering. New York: North-Holland.

[17] Reason, J. (1990). Human error. Cambridge: Cambridge University Press.

[18] Lee, S.J., Kim, M.C., Seong, P.H. (2008). An analytical approach to quantitative effect estimation of operation advisory system based on human cognitive process using the Bayesian belief network. Reliability Engineering \& System Safety, 93(4): 567-577. https://doi.org/10.1016/j.ress.2007.02.004

[19] Thompson, C.M., Cooper, S.E., Bley, D.C., Forester, J.A., Wreathall, J. (1997). The application of ATHEANA: A technique for human error analysis. Proceedings of the 1997 IEEE Sixth Conference on Human Factors and Power Plants, 1997. 'Global Perspectives of Human Factors in Power Generation'. https://doi.org/10.1109/HFPP.1997.624860

[20] Barriere, M., Bley, D., Cooper, S., Forester, J., Kolaczkowski, A., Luckas, W. (2000). Technical basis and implementation guideline for a technique for human event analysis (ATHEANA). NUREG-1624, Rev. 1, 2000, US Nuclear Regulatory Commission, Washington,
DC.

[21] Coal mine safety net, Compilation of cases of coal mine transportation lifting accidents [EB/OL]. http://www.mkaq.org/sggl/shigual/, accessed on Sep. 17, 2020.

[22] National Coal Mine Safety Administration [EB/OL]. https://www.chinacoal-safety.gov.cn/, accessed on Sep. $17,2020$.

[23] Li, P.C., Zhang, L., Dai, L.C. (2015). Operator's cognitive activities and errors analysis in nuclear power plants. Industrial Engineering and Management, 2015(1): 128-134. https://doi.org/10.3969/j.issn.10075429.2015 .01 .020

[24] Koch, C., Ullman, S. (1987). Shifts in Selective Visual Attention: Towards the Underlying Neural Circuitry. In: Vaina L.M. (eds) Matters of Intelligence. Synthese Library (Studies in Epistemology, Logic, Methodology, and Philosophy of Science), 188: 115-141. https://doi.org/10.1007/978-94-009-3833-5_5

[25] Itti, L., Koch, C., Niebur, E. (1998). A model of saliencybased visual attention for rapid scene analysis. IEEE Transactions on Pattern Analysis \& Machine Intelligence, 20(11): 1254-1259. https://doi.org/10.1109/34.730558

[26] Itti, L., Koch, C. (2001). Computational modelling of visual attention. Nature Reviews Neuroscience, 2(3): 194-203. https://doi.org/10.1038/35058500

[27] Wickens, C.D., Helleberg, I., Goh, J., Xu, X., Horrey, W.J. (2001). Pilot Task Management: Testing an Attentional Expected Value Model of Visual Scanning (ARL-0114/NASA-01-7). Savoy, IL: University of llinois, Aviation Research Lab.

[28] Wickens, C.D., Goh, J., Helleberg, J., Horrey, W.J., Talleur, D.A. (2003). Attentional models of multitask pilot performance using advanced display technology. Human Factors, 45(3): 360-380. https://doi.org/10.1518/hfes.45.3.360.27250

[29] Wang, X.P. (2011). Management System Engineering: Methodology and Modeling. Beijing: China Machine Press. 